\title{
Evaluation of patients with ischemic heart disease by thallium-201 myocardial imaging
}

\begin{abstract}
Thallium-201 myocardial imaging at rest and during exercise has found wide application in the evaluation of patients with suspected ischemic heart disease. Although the reported sensitivity of this technique is approximately $80 \%$ and the specificity $90 \%$, the actual sensitivity and speciflcity are likely to be considerably higher. Only by careful attention to improvements in technical factors and in our ability to determine whether myocardial ischemia is present at rest or during exercise in patients being evaluated in the catheterization laboratory by arteriography will we be able to define the true sensitivity and specificity of this or other new noninvasive techniques. (AM HEART J 103:784, 1982.)
\end{abstract}

Bertram Pitt, M.D., and James H. Thrall, M.D., Ann Arbor, Mich.

In the initial study of exercise thallium-201 myocardial imaging to detect patients with ischemic heart disease, ${ }^{1}$ an overall sensitivity of $86 \%$ was found. This sensitivity is significantly better than that for exercise ECG. That study also showed that the sensitivity of thallium-201 myocardial imaging in detecting significant coronary artery disease is partially dependent on the extent of the anatomic disease; for example, in patients with triple-vessel disease, the sensitivity was $98 \%$. Since then there have been several reports of exercise thallium-201 myocardial imaging to detect patients with significant anatomic coronary artery disease. A survey of the published data on over 1800 patients from several centers has been summarized by Okada et al. ${ }^{2}$ The overall sensitivity reported in these studies was $82 \%$, with a specificity of $91 \%$. In comparison, the sensitivity of exercise ECG was $60 \%$, with a specificity of $81 \%$. These values are similar to those reported initially ${ }^{1}$ and account for the relatively rapid acceptance and wide application of this technique in evaluating patients with suspected ischemic heart disease. It should, however, be emphasized that the overall sensitivity of exercise thallium-201 myocardial inaging in comparison with exercise ECG depends on patient selection. For example, for patients with a normal resting ECG, the relative sensitivity of the two techniques, at least from visual interpretation of planar thallium-201 myocardial imaging, will not be markedly different. On the

From the Division of Cardiology, Division of Nuclear Medicine, Department of Internal Medicine, University of Michigan Medical Center.

Reprint requests: Bertram Pitt, M.D., Cardiology Division, University Hospital, 1405 East Ann St., Ann Arbor, MI 48109. other hand, if patients have resting ST-T wave abnormalities, evidence of previous myocardial infarction, or the presence of intraventricular conduction defects, the sensitivity of exercise thallium201 myocardial imaging will be significantly greater than that for exercise ECG. ${ }^{1}$ Some recent attempts to improve the use of thallium-201 myocardial imaging in evaluating patients with suspected ischemic heart disease are reviewed here.

\section{SPECIFICITY OF THALLIUM-201 MYOCARDIAL IMAGING TO DETECT PATIENTS WITH ISCHEMIC HEART DISEASE}

Although the currently reported specificity of exercise thallium-201 myocardial imaging is approximately $90 \%$, there is reason to believe that the actual tigure may be higher. A study by Lösse et al. ${ }^{3}$ suggests that the incidence of false positive exercise thallium-201 myocardial images may not be as great as previously thought. These investigators examined a number of patients with precordial chest pain suggestive of myocardial ischemia who had an abnormal exercise thallium-201 myocardial image but normal coronary arteries and left ventricular function at cardiac catheterization. In many of them, lactate production and abnormal myocardial biopsies suggested a metabolic defect. Opherk et al. ${ }^{4}$ also point out a risk in assuming that patients with normal coronary arteries and left ventricular function do not have ischemic heart disease. They found a group of patients with chest pain suggestive of myocardial ischemia who had normal coronary arteries and left ventricles on angiography. Their myocardial flow reserve, as assessed by the argon washout technique, however, was significantly decreased. Myocardial biopsies revealed swollen 
mitochondria and myelin bodies. ${ }^{4}$ Other centers have also reported that patients with a positive exercise thallium-201 myocardial image but a normal coronary arteriogram may have a high incidence of hypertension and abnormal left ventricular function. Similarly, patients with left ventricular hypertrophy due to aortic stenosis ${ }^{5}$ or some other cause such as hypertrophic cardiomyopathy ${ }^{6}$ may have an abnormal exercise thallium-201 myocardial image but normal coronary arteries on angiography. The abnormal image in this circumstance probably indicates myocardial ischemia due to altered flow reserve, oxygen transport, and/or flow distribution. Another cause of false positive exercise thallium-201 myocardial images may be coronary artery spasm. It has recently been emphasized that some patients with normal coronary arteries may have exerciseinduced coronary artery spasm. ${ }^{\text {? }}$

Other errors in designating an image as being false positive may be due to a failure of the coronary arteriogram to predict accurately the extent of the anatomic coronary artery narrowing. It is well known that there is considerable interobserver and intraobserver variation in interpreting clinical coronary arteriograms. For example, one observer may classify a lesion as critical (i.e., $>50 \%$ to $70 \%$ narrowing), depending on the criteria used in the given laboratory, whereas another observer or the same observer at another time may classify the lesion as being subcritical. Thus a positive thallium201 image may be classified as being a false positive on one occasion and a true positive on another. This has led our own and other groups to develop new computer techniques in the catheterization laboratory to analyze coronary arteriograms. One technique that has shown promise is the use of a new image-processing computer, the cytocomputer. ${ }^{8}$ Rather than looking at changes in every pixel in the computer as a separate event, the cytocomputer looks at neighborhood transformations such that a process can be carried out simultaneously on every pixel. The design of the computer and software allows the application of new edge-detection algorithms to define accurately the extent of coronary artery narrowing. Although work on this technique is still in a relatively early stage, it appears likely that with this and other recent developments in computer analysis and quantitative coronary angiography, we will be able to determine the extent of coronary narrowing in the coronary arteriogram with little or no observer error. If we are to be critical in evaluating new noninvasive techniques such as thallium-201 myocardial imaging, it is essential that we be equally critical in evaluating coronary arterio- grams, which in most centers remain the "gold standard" against which noninvasive tests are compared.

Regardless of how accurately we determine the extent of coronary artery narrowing from a coronary arteriogram, it is apparent that there may be significant overestimation or underestimation of the true extent as determined at postmortem examination. Thus a diffuse narrowing of a major vessel that may be functionally significant may not be readily detected as being significant by arteriography. The limitations of current arteriographic techniques in estimating the functional significance of a given anatomic lesion can be seen in the studies of Marcus et al. ${ }^{9}$ These investigators have measured coronary artery flow reserve in patients referred for coronary artery bypass graft surgery by using a new Doppler flow transducer. ${ }^{9}$ They have found that some patients with coronary artery narrowing of less than $50 \%$ on arteriography have a significant reduction in coronary flow reserve, suggesting that the lesion is functionally significant. The designation of a positive exercise thallium-201 defect in a patient with $<50 \%$ narrowing on arteriography as false positive may therefore be unjustified. Classification of a new exercise thallium-201 defect as a true false positive in a patient with $<50 \%$ narrowing on arteriography would require the exclusion of reduced coronary artery flow reserve, ${ }^{4}$ ventricular hypertrophy, ${ }^{5}$ or exercise-induced coronary artery spasm ${ }^{7}$ or the use of other functional and metabolic tests to exclude the possibility that the lesion is functionally significant and could account for the patient's symptoms and positive exercise thallium-201 image. Other causes of false positive exercise thallium-201 images, such as soft tissue attentuation due to breast tissue or diaphragm ${ }^{10}$ or normal apical thinning, ${ }^{11}$ should be more easily recognized. Extensive experience in visual interpretation of thallium-201 myocardial images and the use of multiple views should in part reduce these errors and improve the specificity of the technique.

The incidence of false positive interpretations can be further reduced by applying new quantitative approaches to the interpretation of thallium-201 myocardial imaging. In one approach advocated by Berger et al., ${ }^{12}$ computer analysis of the change in thallium-201 activity from the exercise to the postexercise redistribution image after background correction has enabled normal and abnormal areas of myocardium to be defined more accurately. Normal areas of myocardium tend to lose thallium-201 activity over time, whereas ischemic areas increase their activity. With this computer technique, they 
were able to increase the specificity of exercise thallium-201 myocardial imaging to $90 \%$, from a value of $73 \%$ obtained with visual interpretation.

One subset of patients in which there is uncertainty as to the cause of a positive thallium-201 image and in whom the thallium image may be a true positive includes those with mitral valve prolapse. Positive exercise thallium-201 myocardial images are occasionally encountered in these patients without any evidence of obstructive coronary artery disease of myocardial ischemia. Their exercise thallium-201 defect may be due to an abnormality of regional myocardial wall thickening rather than to ischemia itself. Abnormal thallium-201 myocardial images have been found occasionally to be due to ventricular dilation and myocardial wall thinning rather than to ischemia. $^{13}$

The true specificity of exercise thallium-201 myocardial imaging in evaluating patients with suspected myocardial ischemia is as yet undetermined. The actual specificity of this technique-or for that matter, any noninvasive technique-for detecting myocardial ischemia will depend on the definition used: e.g., the presence of anatomic obstructive coronary artery disease; spasm; metabolic evidence of ischemia, such as lactate production or hypoxanthine release; or evidence of functional impairment, such as the development of an abnormality of regional myocardial wall motion or thickening. Although exercise thallium-201 myocardial imaging will not achieve $100 \%$ specificity for evaluating patients with suspected myocardial ischemia regardless of the definition used, it is likely that the true specificity of the technique will be considerably greater than that currently reported.

\section{SENSITIVITY OF EXERCISE THALLIUM-201 MYOCARDIAL IMAGING IN PATIENTS WITH SUSPECTED ISCHEMIC HEART DISEASE}

Many of the same difficulties encountered in classifying an exercise thallium-201 myocardial image as being false positive are found in classifying an image as false negative. Although the reported sensitivity of rest and exercise thallium-201 myocardial imaging for detecting patients with coronary artery disease is approximately $80 \%$, the true sensitivity has not as yet been determined. For example, in most laboratories, a patient with a $70 \%$ narrowing of a major coronary artery on arteriography and a negative rest and exercise thallium-201 myocardial image would be classified as having a false negative thallium-201 image, thereby reducing the sensitivity of the technique. It must be emphasized, however, that the exercise thallium-201 myocardial image is a test of myocardial ischemia rather than of anatomic coronary artery narrowing. Although most lesions with narrowing of $70 \%$ or more are functionally significant, some are not. In the study by Marcus et al., ${ }^{9}$ in which coronary artery flow reserve was measured at the time of coronary artery bypass graft surgery, some patients with $>70 \%$ coronary artery narrowing determined at angiography had a normal flow reserve. A negative exercise thallium-201 myocardial image in such a patient, although classified in most series as a false negative, is actually a true negative, because the lesion is functionally insignificant despite the arteriographic findings. True negative exercise thallium-201 images in the presence of a $>70 \%$ coronary artery narrowing determined at coronary angiography may be due to subjective errors in interpreting the arteriogram, a relatively short lesion that does not impair the flow reserve to the same degree as a longer lesion of the same or lesser narrowing, inadequate stress to produce ischemia, or the presence of collateral vessels. ${ }^{14}$

Although physiologic considerations may account for some of the false negative exercise thallium-201 myocardial images and hence a sensitivity of only $80 \%$, an equally or even more important reason for the occurrence of a false negative image may be such technical considerations as the dose, imaging technique, camera resolution, or inexperience in visual interpretation.

Several groups have tried to reduce the errors associated with visual interpretation by developing quantitative computer-based approaches. One such approach, ${ }^{12}$ in which the change in thallium-201 activity is computed from the stress to the subsequent redistribution image, has found a sensitivity of $91 \%$ for detecting significant coronary artery disease. In this study, the computer-based approach predicted multivessel disease in $78 \%$ of the instances, compared with only $39 \%$ predicted by standard qualitative techniques. ${ }^{12}$ The relatively good sensitivity of the quantitative approach in detecting significant obstructive coronary artery disease was made possible by the fact that ischemia could be predicted from the quantitative analysis of the changes in thallium-201 activity from stress to redistribution even in circumstances where a visual thallium-201 defect was not present. Other groups have attempted to increase the sensitivity of exercise thallium-201 myocardial imaging by determining lung thallium-201 uptake during exercise. ${ }^{15}$ An increased lung thallium-201 uptake has been shown to correlate with the severity of coronary artery disease and left ventricular dysfunction and has been found to be associated with the elevated pul- 
monary venous pressure that often occurs during myocardial ischemia. In occasional patients with diffuse subendocardial ischemia in whom a defect in thallium-201 uptake is not detected by visual interpretation, the finding of an elevated lung thallium201 uptake may be an important clue to the presence of significant coronary artery disease. Although the calculation of lung thallium-201 uptake may increase the sensitivity of exercise thallium-201 myocardial imaging with visual interpretation, it is less certain that this approach will increase the sensitivity if quantitative approaches to image interpretation $^{12}$ are used.

The sensitivity of exercise thallium-201 myocardial imaging has also been shown to be increased by tomographic imaging techniques without sacrificing specificity. In a recent study in our laboratory ${ }^{16}$ we used a seven-pinhole tomographic collimator for exercise thallium-201 imaging. We obtained a sensitivity of $94 \%$, compared with only $75 \%$ when the same patients were studied with a conventional collimator. The relatively excellent sensitivity obtained with seven-pinhole tomography both in our own and other laboratories depends on meticulous attention to positioning, ${ }^{16}$ which is far more critical with the seven-pinhole collimator than with standard collimators. Without precise positioning, errors will appear in one or more of the pinhole images, leading to both false positive and negative images.

Other tomographic collimator systems such as the coded-aperture collimator designed at the University of Michigan also appear to have promise for improving the sensitivity of exercise thallium-201 myocardial imaging. A recent study from our institution has shown the utility of this collimator in evaluating the extent of myocardial infarction. The correlation between tomographically and pathologically determined total left ventricular mass was 0.87 ; infarct mass, 0.90; and percent of the left ventricle that was infarcted, $0.87 .{ }^{17}$ Although collimator approaches to tomographic imaging are promising for improved sensitivity and better quantitation of the extent of myocardial ischemia or infarction, each has certain inherent limitations that make precise quantitation difficult. Another tomographic approach being pursued in our institution and elsewhere is the use of rotating detectors. A commercial version, the General Electric 400-T tomographic camera, is now undergoing extensive evaluation. It is still too early to determine whether this approach will improve the sensitivity of exercise thallium-201 imaging, but the initial data suggest that it will provide advantages over conventional thallium-201 imaging for quantitation of the extent of ischemia or infarction.

The specificity and sensitivity data for thallium201 myocardial imaging have been used in conjunction with Baye's theorem to predict the clinical utility of a positive or negative exercise image in subsets of patients with different prevalences of significant coronary artery disease. ${ }^{18}$ This approach is useful in predicting that in populations with a high prevalence of disease, such as those with typical exertional angina pectoris, a negative exercise thallium-201 image may have limited utility in view of the imperfect sensitivity of the technique, whereas in subsets with a low prevalence of disease, such as asymptomatic patients a positive exercise thallium201 image will also have limited utility in view of the imperfect specificity of the technique. While this general approach appears valid, it must be emphasized that we do not yet know the true specificity or sensitivity of exercise thallium-201 myocardial imaging for detecting myocardial ischemia. It is likely that the true specificity is greater than the $90 \%$ reported from the cumulative experience in over 1800 patients and the true sensitivity greater than $82 \%^{2}$ and even possibly greater than the $94 \%$ reported with seven-pinpole tomographic imaging. ${ }^{16}$ Only after the true specificity and sensitivity of exercise thallium-201 myocardial imaging are known will we be able to apply Baye's theorem and a posttest likelihood analysis properly to determine the role of this technique in clinical decision making. The combination of exercise thallium-201 myocardial imaging with other noninvasive techniques, such as exercise ECG or exercise blood-pool imaging, should enable accurate predictions to be made as to the presence of absence of myocardial ischemia in subsets with high and low prevalences of disease. Exercise thallium-201 myocardial imaging in conjunction with exercise ECG has been found to be useful in predicting the presence of significant obstructive coronary artery disease in asymptomatic individuals. $^{19}$

\section{CONCLUSIONS}

It is possible that new technetium-99m-labeled myocardial imaging agents currently being developed might replace thallium-201 in evaluating patients with suspected myocardial ischemia. Unless we begin to define and determine the presence or absence of myocardial ischemia more accurately both at rest and during stress and distinguish ischemia from the anatomic presence of obstructive coronary artery disease, it is unlikely that we will know the true specificity or sensitivity of thallium 
201 or other new myocardial imaging agents in evaluating patients with suspected coronary artery disease.

\section{REFERENCES}

1. Bailey IK, Griffith LSC, Rouleau J, Strauss HW, Pitt B: Thallium-201 myocardial perfusion imaging at rest and exercise: Comparative sensitivity to electrocardiography in coronary artery disease. Circulation 55:79, 1977.

2. Okada RD, Boucher CA, Strauss HW, Pohost GM: Exercise radionuclide imaging approaches to coronary artery disease. Am J Cardiol 46:1188, 1980.

3. Lösse B, Kuhn H, Raffenbuhl D, Kronert IT, Hart W, Feinendegen LE, Loogen E: Thallium-201 myocardial scintigraphy in patients with normal coronary arteries and normal left ventriculogram: Comparison with hemodynamics, metabolic and morphologic findings. Z Kardiol 69:523, 1980.

4. Opherk D, Zebe H, Weihe E, Mall G, Dürr C, Gravert B, Mehmel HC, Schwarz F, Kubler W: Reduced coronary dilatory capacity and ultrastructural changes in the myocardium in patients with angina pectoris but normal coronary arteriograms. Circulation 63:817, 1981.

5. Bailey IK, Come PC, Kelly DT, Burow RD, Griffith LSC, Strauss HW, Pitt B: Thallium-201 myocardial perfusion imaging in valvular aortic stenosis. Am $\mathrm{J}$ Cardiol 40:889, 1977.

6. Pitcher D, Wainwright R, Maisey M, Curry P, Sowton E: Assessment of chest pain in hypertrophic cardiomyopathy using exercise thallium-201 myocardial scintigraphy. $\mathrm{Br}$ Heart J 44:650, 1980.

7. Yasue $\mathrm{H}$, Omote $\mathrm{S}$, Takizawa A, Nogao $M$, Taraka $\mathrm{S}$ : Exertional angina pectoris caused by coronary artery spasm: Effects of various drugs. Am J Cardiol 43:647, 1979

8. Smith DN, Colfer H, Brymer JF, Pitt B, Kliman SH: A semiautomatic computer technique for processing coronary angiograms. Florence, Italy, 1981, Computers in Cardiology.

9. Marcus ML, Wright C, Doty D, Eastham C, Laughlin D, Crumm P, Fastenow C, Brody M: Measurement of coronary velocity of reactive hyperemia in the coronary circulation of humans. Circ Res 49:873, 1981.

10. Dunn RF, Wolff L, Wagner S, Botvinick EH: 'T'he inconsistent pattern of thallium defects: A clue to the false positive scintigram. Am J Cardiol 48:224, 1981.

11. Cook DJ, Bailey I, Strauss HW, Rouleau J, Wagner HN, Pitt $B$ : Thallium-201 for myocardial imaging: Appearance of the normal heart. J Nucl Med 17:583, 1976.

12. Berger BC, Watson DD, Taylor GJ, Craddock GB, Martin RP, Teates CD, Beller GA: Quantitative thallium-201 exercise scintigraphy for detection of coronary artery disease. $\mathrm{J}$ Nucl Med 22:585, 1981.

13. Gewirtz H, Grotte GJ, Strauss HW, O'Keefe DD, Akins CW, Daggett WM, Pohost GM: The influence of left ventricular volume and wall motion on myocardial images. Circulation 59:1172, 1979

14. Rigo P, Becker LC, Griffith LSC, Alderson PO, Bailey IK,
Pitt B, Burow RD, Wagner HN Jr: Influence of coronary collateral vessels on the results of thallium-201 myocardial stress imaging. Am J Cardiol 44:452, 1979.

15. Kushner FG, Okada RD, Kirsherbaum HD, Boucher CA, Strauss HW, Pohost GM: Lung thallium-201 uptake after stress testing in patients with coronary artery disease. Circulation 63:341, 1981

16. Rizi HR, Kline RC, Thrall JH, Besozzi MC, Keyes JW Jr, Rogers WL, Clare J, Pitt B: Thaltium-201 myocardial scintigraphy: A critical comparison of seven pinhole tomography and conventional planar imaging. J Nucl Med 22:493, 1981.

17. Keyes JW Jr, Brady TJ, Leonard PF, Svetkoff OB, Winter SM, Rogers WL, Rose EA: Calculation of viable and infarcted mass from thallium-201 tomograms. J Nucl Med 22:239, 1981

18. Hamilton GW, Trobaugh GB, Ritchie JL, Gould KL, DeRaven TA, Williams DA: Myocardial imaging with 201-thallium: An analysis of clinical usefulness based on Baye's theorem. Semin Nucl Med 7:358, 1978.

19. Caralis DG, Bailey I, Kennedy HI, Pitt B: Thallium-201 myocardial imaging in evaluation of asymptomatic individuals with ischemic ST segment depression on exercise electrocardiogram. Br Heart J 42:562, 1979.

\section{DISCUSSION}

Dr. Surawicz: Please comment on the cost of thallium201 imaging.

Dr. Pitt: The cost varies from center to center. In our institution, the cost of exercise thallium-201 imaging is approximately $\$ 300$, and the cost of a dose of thallium-201 is about $\$ 80$. The total cost is therefore considerably higher than an exercise ECG. In patients with a baseline abnormality on the ECG, it may be more cost effective to perform exercise thallium-201 myocardial imaging than an exercise ECG in view of the greater specificity and sensitivity of thallium-201 imaging under these circumstances.

Dr. Gorlin: Much work has been done with coronary vasodilators in an attempt to increase flow differences between normal areas of myocardium and areas served by a narrowed vessel. Did you deliberately avoid this topic because all the work has been done and there is no future to it, or did you run out of time?

Dr. PItt: I believe that maximal vasodilators as a substitute for exercise are useful in thallium-201 imaging. In fact, Dr. H. William Strauss and I were the first to propose this approach. In our original publication (Strauss HW, Pitt B: Am J Cardiol 39:403, 1977), we used ethyl adenosine as a maximal vasodilator and demonstrated its utility in detecting areas of ischemia. 